
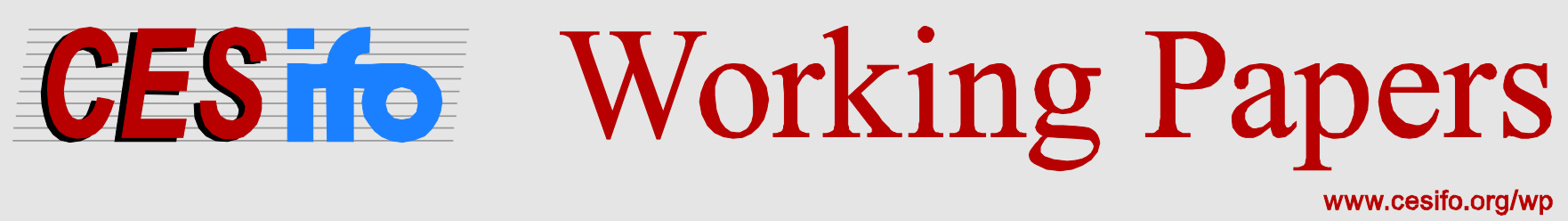

\title{
Foreign Direct Investment Modes and Local Backward Linkages
}

\author{
Chrysovalantou Milliou \\ Apostolis Pavlou
}

CESIFO WORKING PAPER NO. 4623

CATEGORY 11: INDUSTRIAL ORGANISATION

FEBRUARY 2014

An electronic version of the paper may be downloaded

- from the SSRN website:

- from the RePEc website:

- from the CESifo website:

WWW.SSRN.com

www.RePEc.org

www.CESifo-group.org/wp

\section{CESifo}




\title{
Foreign Direct Investment Modes and Local Backward Linkages
}

\begin{abstract}
We study a multinational enterprise's (MNE) choice of foreign direct investment (FDI) mode in a vertically related market with local input sourcing. We show that the vertical structure of the market and its features play a crucial role for the MNE.s decision: backward linkages, enhanced upstream bargaining power, use of non-linear contracts, and interim unobservability of contract terms favor cross-border acquisition relative to greenfield investment. We also show that while a cross-border acquisition reduces welfare, greenfield investment can be welfare-improving. These results suggest that policy should distinguish among FDI modes as well as among markets with more or less dependence on backward linkages.
\end{abstract}

JEL-Code: L130, F120, F230.

Keywords: foreign direct investment, greenfield investment, acquisition, vertical relations, two-part tariffs.

\author{
Chrysovalantou Milliou \\ Department of International \& \\ European Economic Studies \\ Athens University of Economics and \\ Business \\ Greece - Athens 10434 \\ cmilliou@aueb.gr
}

\author{
Apostolis Pavlou \\ Department of Economics \\ Athens University of Economics and \\ Business \\ Greece - Athens 10434 \\ pavlou@aueb.gr
}

January 2014

We would like to thank Maria Alipranti, Stephane Caprice, Jean Gabszewicz, Emmanuel Petrakis, Joel Sandonis, and the conference participants at GAEL 2013 at Grenoble and at EARIE 2013 at Evora for their useful comments. This research has been co-financed by the European Union (European Social Fund - ESF) and Greek national funds through the Operational Program "Education and Lifelong Learning” of the National Strategic Reference Framework (NSRF) - Research Funding Program: Thalis - Athens University of Economics and Business - "New Methods in the Analysis of Market Competition: Oligopoly, Networks and Regulation”. Full responsibility for all shortcomings is ours. 


\section{Introduction}

Foreign direct investment (FDI) constitutes the prevailing channel of serving foreign markets. ${ }^{1}$ Consequently, in an increasingly globalized world, the firms that undertake FDI, the multinational enterprises (MNEs), are of significant importance. One of the key challenges that MNEs face is the choice of their FDI mode. Between 1996 and 2005, most FDI was carried out through the acquisition of foreign firms rather than through the establishment of new firms abroad, known as greenfield investment. During the same period, the value of cross-border mergers and acquisitions (M\&As) was approximately $70 \%$ of the global FDI flows (UNCTAD, 2006). Since 2008 though, greenfield investments outweigh cross-border M\&As (UNCTAD, 2012).

The dominant mode of FDI varies not only across time, but also across host countries with different development levels. In the last twenty years, whereas the main form of FDI in industrialized countries is cross-border M\&A (Miyamoto, 2003; UNCTAD, 2008 and 2012), in developing countries it is greenfield investment. In fact, in 2011, more than two thirds of the total value of greenfield investments was hosted by developing and transition countries (UNCTAD, 2012).

Independently of its mode, FDI often results into local backward linkages. These linkages are created when the manufacturing plants that MNEs operate abroad purchase intermediate products from their host country's local suppliers. Such a practise is a commonplace. For instance, Volvo, the Swedish manufacturer of heavy commercial vehicles, sources a substantial share of parts and components (e.g., metals and alloys, machine castings and forgings, gearboxes, axles) for the vehicles that it manufactures in its plants in Brazil, Mexico, China, and India, from local input producers. The amount of local content in its vehicles ranges from one-third of their gross added value in India to almost two-thirds in China and Brazil (Ivarsson and Alvstam, 2005). ${ }^{2}$ Similarly, affiliates of Taiwanese MNEs in China and in the US source more than $35 \%$ of their inputs locally (Liu, 2011), MNEs in the Mexican car, chemical and electronics industries purchase about $26 \%$ of their material inputs from local firms (Jordaan, 2011), MNEs in the textiles and electronics sectors in Malaysia source one-third of their material inputs locally (Giroud, 2007), MNEs in Latvia purchase $47 \%$ of their inputs from Latvian producers (World Bank, 2003). ${ }^{3}$

Despite the prevalence of backward vertical linkages in many host countries and industries, their role in the choice of FDI mode has not been explored yet. The existing theoretical

\footnotetext{
${ }^{1}$ The aggregate sales by foreign affiliates exceed the world exports for more than three decades (UNCTAD, 2004 and 2012).

${ }^{2}$ Ivarsson and Alvstam (2005) also document that Volvo's local purchases are concentrated to a relatively small number of dominant suppliers.

${ }^{3}$ MNEs engange in local procurement because of the lower transporation costs and the better monitoring (UNCTAD, 1999) or because of policy restrictions such as local content requirements imposed by the host country's government (Qiu and Tao, 2001).
} 
literature on FDI has been preoccupied with analyzing the FDI mode choice in one-tier markets, neglecting the fact that most MNEs operate in vertically related markets and source inputs from local upstream suppliers. To the extent though that vertically related markets differ significantly from one-tier markets, the choice of FDI mode and its implications in such markets cannot be fully understood without taking into account the role of their distinct features, i.e., without modeling explicitly their vertical structure and the backward linkages.

In this paper, we endogenize a MNE's choice of FDI mode, cross-border M\&A or greenfield investment, in a vertically related market with local input sourcing. In our model, a MNE considers entering into a host market that consists of a domestic upstream input supplier and two domestic downstream final product manufacturers. The MNE can enter either by creating a new downstream firm (greenfield investment) or by acquiring one of the domestic downstream firms (acquisition). Under greenfield investment, the MNE incurs a fixed cost for setting up its new production plant, while under acquisition, it pays an endogenously determined acquisition price. Upon entry, the MNE sources an essential input from the domestic upstream supplier after bargaining over the input price and competes in quantities with the domestic downstream firm(s).

We focus on situations in which the upstream monopolist secretly contracts with the competing downstream firms, i.e., it contracts separately and simultaneously with each of them. We consider two different contract types: two-part tariff contracts and wholesale price contracts. We also consider two different information structures: all the contract terms are observed by all the downstream firms before competing in the final market (interim observability) or each downstream firm observes only its own contract terms before choosing its output (interim unobservability). This last distinction is motivated by the fact that in some markets information regarding the rivals' contract terms might be more easily accessible than in others. Importantly, it is motivated by the fact that recently, in some, but not in all, industry sectors, regulations that do not permit that the wholesale prices offered to vertical partners are confidential have been adopted. For instance, the Danish government requires the disclosure of the wholesale price contracts in the market for the supply of ready-to-mix concrete. Similarly, the U.S. government has made efforts to mandate the disclosure of the medical equipment and pharmaceutical costs at the wholesale level. ${ }^{4}$

Our work contributes to the better understanding of the implications of the different modes of FDI as well as of the preferences of the MNEs among them through the following three ways:

First, by exploring how a number of characteristics of vertically related markets influence a MNE's decision about how to serve a foreign market. We find that higher upstream bargaining power, as well as stronger downstream competition, reinforces the incentives of the MNE to expand through acquisition rather than through greenfield investment. Intuitively, under

\footnotetext{
${ }^{4}$ For more details on this and for an analysis of the incentives and the implications of such disclosure requirements see Arya and Mittendorf (2011) and Piccolo and Miklós-Thal (2012).
} 
acquisition the MNE has to compensate the domestic acquired firm for the profits that the latter would make otherwise, i.e., its profits under greenfield investment. The gross profits of the MNE under both FDI modes decrease when the upstream input supplier becomes more powerful or the downstream competition gets more intense. This in turn means that the acquisition price decreases then, and thus, that acquisition becomes cheaper and more attractive. These findings provide a theoretical justification for the empirically observed dominance of cross-border M\&As in developed countries and of greenfield invest in developing countries. They suggest that the MNEs might have a stronger preference for acquisition in developed countries because their markets are characterized by more powerful input suppliers and fiercer competition than the markets of the developing countries.

Undoubtedly, besides the distribution of bargaining power, another important feature of a vertically related market is the type of contract type employed. Contracts can take and do take in reality many different forms, from linear wholesale price contracts to more complex non-linear tariffs. ${ }^{5}$ We show that the contract type plays a crucial role in the FDI mode choice. In particular, we show that two-part tariffs favor acquisition relative to greenfield investment more than wholesale price contracts, unless the upstream bargaining power is sufficiently low. This results in mainly driven from the fact that the domestic upstream supplier extracts, due to the fixed fees, a larger share of the generated surplus with two-part tariffs than with wholesale price contracts.

We also show that the observability of the contract terms before the output choices, and hence, the regulations that impose it, can affect the equilibrium input prices and, more importantly, the way through which MNEs expand. By increasing the severity of the upstream monopolist's commitment problem, contract terms' observability results into lower input prices, and thus, into higher downstream efficiency with greenfield investment than with acquisition. Therefore, greenfield investment has an advantage then relative to acquisition which is missing when contract terms are fully unobservable.

Second, by distinguishing among vertically related markets and one-tier markets, and thus, between markets with and without local backward linkages. Thus, by introducing to the literature on FDI a new element that can affect firms choice of FDI mode. We show that this distinction is a critical determinant of the mode of international investments. Firms that operate in markets where they obtain their inputs from a concentrated upstream market might have stronger incentives to engage in acquisition rather than in greenfield investment than firms that operate in markets where they produce their inputs in house. This arises mainly because in a vertically related market, the downstream firms do not fully extract the surplus that they

\footnotetext{
${ }^{5}$ Smith and Thanassoulis (2009), for instance, report that in the UK milk industry firms trade through wholesale price contracts. In contrast, in the US yoghourt market and in the bottle water market in France, Villas-Boas (2007) and Bonnet and Dubois (2010) find respectively empirical evidence for the dominance of two-part tariffs.
} 
generate in the market - the upstream supplier gets part of the surplus through the contract terms.

The distinction between vertically related markets and one-tier markets has wide-ranging implications for empirical work. A fast-growing empirical literature explores how backward linkages affect the implications of FDI on the host countries (e.g., Javorcik, 2004; Blalock and Gertler, 2008; Barrios et al., 2011; Jordaan, 2011; Liu, 2011). However, only a small part of this literature distinguishes between the different modes of FDI. Moreover, to the best of our knowledge, this literature ignores the role of the upstream structure and its characteristics (e.g., presence of powerful input suppliers) in the trade-off between greenfield investments and cross-border M\&As. Our finding give rise to the following testable implication: cross-border M\&As are more likely to be observed relative to greenfield investments in industries where firms obtain inputs from a concentrated upstream market than in industries where inputs are either produced in-house or sourced from a perfectly competitive upstream market.

Third, by pointing out that the two FDI modes differ significantly in terms of their impact on the host country's economy. In particular, we find that FDI through greenfield investment, by increasing both the intensity of downstream competition and the number of local backward linkages, can cause an increase in the host country's consumers' surplus, upstream profits and total welfare. This is not the case through for FDI through acquisition which is always welfaredetrimental. Importantly, if we had not allowed for acquisition as a possible FDI mode, our conclusions regarding the desirability of FDI would be quite different. This would also be the case if we had not taken into account the role of backward linkages.

These results highlight the need that the policy towards FDI distinguishes among the different FDI modes. Furthermore, they highlight that it should also distinguish among industry sectors with different features, such as their degree of dependence on input suppliers and the concentration in the inputs market.

Our paper blends elements of the international economics literature on FDI with elements of the industrial organization literature on vertically related markets. A recent branch of the former literature seeks to understand how a number of market features, such as market size (Eicher and Kang, 2005; Müller, 2007; Qiu and Wang, 2011), FDI policy (Qiu and Wang, 2011), and differences in cost efficiency (Mattoo et al., 2004; Eicher and Kang, 2005; Müller, 2007) as well as in product quality (Gabszewicz et al., 2011), shape the mode of FDI. ${ }^{6}$ This literature has enriched our understanding of the determinants and the host country effects of the different FDI modes, but it has nothing to say about the role of the characteristics of vertically related markets and of the presence of local backward linkages.

Another recent and growing branch of the FDI literature (e.g., Horn and Persson, 2001; Norback and Persson, 2004; Qiu and Zhou, 2006; Neary, 2007; Nocke and Yeaple, 2007 and

\footnotetext{
${ }^{6}$ Allowing for exports, as an alternative expansion mode, Bjorvatn (2004), Eicher and Kang (2005), Müller (2007), and Raff et al. (2009) also examine how the transportation/trade cost affects the expansion mode choice.
} 
2008) attempts to provide a rationale for the prevalence of cross-border M\&As. Qiu and Zhou (2006), for instance, argue that the asymmetric information held between the MNEs and the domestic firms leads to cross-border M\&As. Nocke and Yeaple (2007) and (2008), instead, base their explanation on the heterogeneity of firms and the complementarity in the different capabilities of the MNEs and the domestic acquired firms. Neary (2007) predicts that international differences in technology generate incentives for mergers in which low-cost firms acquire high-cost foreign firms. We complement this literature by offering an alternative explanation for the emergence of cross-border M\&As based on the vertical structure of the market.

To the best of our knowledge, only a handful of theoretical papers study FDI in vertically related markets. ${ }^{7}$ These papers focus on issues related to the vertical technology transfer from the entering MNE to the local suppliers and the subsequent free-riding of the domestic firms (Pack and Saggi, 2001; Goh, 2005; Lin and Saggi, 2007; Balsvik, 2010), the MNE's location choice (Ma, 2012 and 2013; Milliou, 2013), the interdependence between the FDI entry decisions of MNEs into different vertical production stages (Lin and Saggi, 2011), and the local suppliers' technology adoption incentives in the presence of technological incompatibilities among the MNE and the domestic firms (Carluccio and Fally, 2013). ${ }^{8}$ An important feature that we share with these papers is that we assume that input sourcing takes place locally. A key difference, however, is that we consider both greenfield investments and cross-border M\&As, while they restrict their attention to greenfield investments, ignoring the dominance of cross-border M\&As in a number of real world markets. In a notable exception, Beladi et al. (2013) which focus on FDI in a vertically related market though cross-border M\&A. Beladi et al. (2013) though, unlike us, leave out of their analysis greenfield investment and assume that pre-merger the MNE competes with the domestic firms in an international market. ${ }^{9}$ Our paper complements the existing literature on FDI in vertically related markets by addressing the choice among different FDI modes as well as by analyzing the potentially different implications that the alternative FDI expansion modes can have on the economy of the host country.

An additional key difference between our work and the existing literature on FDI in vertically related markets is that we apply a much richer contracting framework which builds on the latest and most sophisticated vertically contracting literature (e.g., O’Brien and Shaffer, 1992; McAfee and Schwartz, 1994; Rey and Vergé, 2004). This literature, similarly to us, focuses

\footnotetext{
${ }^{7}$ In contrast, as mentioned earlier, backward vertical linkages by MNEs have received considerable attention in the empirical literature (see e.g., Javorcik, 2004, Blalock and Gertler, 2008, Barrios et al., 2011, Jordaan, 2011, Liu, 2011).

${ }^{8}$ Rodriguez-Clare (1996) and Markusen and Venables (1999) also study FDI in a vertically related industry. However, they consider a setting with monopolistic competition. Therefore, they abstract from strategic interactions among the MNE and the domestic firms.

${ }^{9}$ Note that Balsvik (2010) examines the choice of a MNE, which operates in the downstream market, among importing its input from its home market, vertically integrating with a local upstream firm, or buying the input from a local upstream firm. In other words, he analyzes the MNE's input sourcing choice, but not the MNE's FDI mode choice since he assumes throughout that the MNE enters through greenfield investment.
} 
on secret contracting through non-linear contracts and demonstrates, among other things, the inability of an upstream supplier to fully exert its market power - its commitment problem. In contrast, the existing literature on FDI in vertically related markets either assumes that the upstream firms compete à la Cournot (Goh 2005; Lin and Saggi, 2007 and 2011), and thus, it does not model explicitly the contracting process or it assumes that vertical trading occurs through linear wholesale price contracts (Pack and Saggi, 2001; Balsvik, 2010; Beladi et al., 2013; Milliou, 2013). ${ }^{10}$ Considering a rich contracting framework, we are the first to explore, in depth, the role of a number of vertical contracting features, such as of the contract types, the observability of the contract terms and the bargaining power distribution, in the FDI mode choice and its implications.

The paper proceeds as follows. The next section describes our model. In section 3, we analyze the differences between the two FDI modes and the MNE's choice among them. Section 4 explores the role of contract terms' observability and contract type for the choice of FDI mode. Section 5 focuses, instead, on the role of the backward linkages. In section 6 , we analyze the implications of FDI and of its different modes on the host country's welfare. The final section, section 7, concludes. All the proofs are relegated to the Appendix.

\section{The Baseline Model}

We consider a host country's market consisting, initially, of a domestic upstream monopolist, denoted by $U$, and two domestic downstream firms, denoted by $D_{1}$ and $D_{2}$. The downstream firms produce a differentiated final good using, in a one-to-one proportion, an intermediate good which they obtain from $U{ }^{11,12}$

A firm from another country - a MNE, contemplates undertaking FDI in the host country in order to sell in its domestic market. ${ }^{13}$ It can choose among two FDI modes. First, it may establish a new production plant in the downstream market of the host country - this is the greenfield investment (GI) mode. Second, it may acquire one of the host country's domestic downstream firms - this is the acquisition (AQ) mode. Under GI, the MNE incurs the fixed cost $G>0$ of setting up a production plant. Under AQ, instead, it pays an endogenously determined price of acquiring one of the domestic firms - the acquisition price, $A$. Under both

\footnotetext{
${ }^{10}$ Lin and Saggi (2007) and Milliou (2013) extend their analysis to non-linear contracts too, but only when they are public.

${ }^{11}$ Note that the intermediate good can also be thought of as specialized/skilled labor that has some market power (for example, due to unionization) or is available in short supply.

${ }^{12}$ The common monopolist supplier case has also been the focus of most of the literature on vertical contracting (see e.g., O'Brien and Shaffer, 1992; McAffe and Schwartz, 1994; Rey and Vergé, 2004).

${ }^{13}$ Note that we implicitly assume that local presence is essential and exclude other ways of serving the host market such as exports. This could be the case when the tariffs that the host country imposes on imports are prohibitively high or that transportation costs are too high. Moreover, this is in fact the case in a number of industry sectors, ranging from construction to telecommunications, where the presence of foreign firms is required in the host country. Clearly, this assumption allows us to focus on the choice of the mode of FDI.
} 
GI and AQ, the MNE's subsidiary in the host country, denoted by $D_{m}$, sources the intermediate product locally, i.e., it obtains it from $U{ }^{14}$

$D_{m}$ competes with the host country's domestic downstream firm(s). In particular, the (inverse) demand faced by each $D_{i}$, with $i=m, 1,2$, in the host country is $p_{i}\left(q_{i}, Q_{-i}\right)=$ $a-q_{i}-\gamma Q_{-i}$, where $p_{i}$ and $q_{i}$ are respectively $D_{i}$ 's price and quantity, and $Q_{-i}$ is the total quantity of its rival(s). The parameter $\gamma$, with $\gamma \in(0,1]$, measures product substitutability; namely, the higher is $\gamma$, the closer substitutes the products of the downstream firms are.

$U$ 's marginal cost of production is given by $u$, with $a>u \geq 0$. $D_{i}$ faces no other cost than the cost of obtaining the input from $U$. The latter consists of a per-unit of input price, $w_{i}$, and a fixed fee, $F_{i}$, i.e., firms trade through non-linear two-part tariff contracts. ${ }^{15}$

The sequence of moves is as follows. First, the MNE chooses its FDI mode: GI or AQ. In case of $\mathrm{AQ}$, it makes an acquisition offer to one of the downstream firms. Given that the downstream firms are symmetric, we assume, without loss of generality, that it makes its acquisition offer to $D_{2}$; it specifies $A$. In turn, $D_{2}$ accepts or rejects the offer. If the offer is rejected, the MNE chooses among GI or no entry at all. Next, $U$ bargains with each $D_{i}$ that operates in the host country's market over $\left(w_{i}, F_{i}\right)$. Lastly, the downstream firms choose their quantities after observing each others' contract terms. ${ }^{16}$

We model bargaining over the contract terms by invoking the Nash equilibrium of simultaneous generalized Nash bargaining problems, in which the bargaining power of an upstream and a downstream firm is given respectively by $\beta$ and $1-\beta$, with $\beta \in[0,1)$. This implies that during the negotiations of a bargaining pair (i.e., between $U$ and $D_{i}$ ) each of its agents takes as given the outcome of the simultaneously-run negotiations of the other bargaining pair(s). A key assumption that underlies this modeling approach is that $U$ bargains with the competing downstream firms simultaneously and separately. This assumption is standard in situations with multilateral contracting (see e.g., Cremer and Riordan, 1987; Horn and Wolinsky, 1988; Hart and Tirole, 1990; O'Brien and Shaffer, 1992; McAfee and Schwartz, 1994 and 1995; Rey and Vergé, 2004; Milliou and Petrakis, 2007; Milliou and Pavlou). ${ }^{17}$ As has been noted by the literature (e.g., McAfee and Schwartz, 1995), multiple equilibria can arise in such settings

\footnotetext{
${ }^{14}$ As mentioned in the Introduction, local sourcing in the context of FDI is empirically relevant. Moreover, local sourcing is a common assumption in the theoretical literature on FDI in vertically related markets, see e.g., Lin and Saggi (2007), Blasvik (2010), and Carluccio and Fally (2013).

${ }^{15}$ In subsection 4.2 , we examine what happens when trading takes place, instead, through linear wholesale price contracts.

${ }^{16}$ As argued in the Introduction, this could be due to increased transparency in the market or to state regulations that require the disclosure of the contracts terms. This case, according to Rey and Vergé's (2004) terminology, is the case of interim observability. In section 4, we examine what happens under interim unobservability, i.e., when in the last stage, each $D_{i}$ observes only its own contract terms.

${ }^{17}$ The rationale for the separate or private negotiations could simply be that the upstream monopolist has various representatives, each negotiating at the same time with a different downstream firm. Two additional justifications are, first, that third parties may be unable to observe others' dealings and verify them in court, and second, that making one contract contingent on the specificities of other contracts may be quite complex and thus difficult to implement (see McAfee and Schwartz, 1995).
} 
due to the multiplicity of the beliefs that the downstream firms can form when they receive out-of-equilibrium offers. Following Horn and Wolinsky (1988), Cremer and Riordan (1987), and O'Brien and Shaffer (1992), we obtain a unique equilibrium by imposing pairwise proofness on the equilibrium contracts. That is, we require that a contract between $U$ and $D_{i}$ is immune to a bilateral deviation of $U$ with a rival downstream firm, holding the contract with $D_{i}$ constant. ${ }^{18}$ An additional key assumption of our bargaining game is that the contract terms of a bargaining pair are not contingent on the disagreement of a rival pair. That is, as in Horn and Wolinsky (1988), O'Brien and Shaffer (1992), McAffe and Schwartz (1994 and 1995), Caprice (2006), and Milliou and Petrakis (2007), we assume that a bargaining pair is unable to write and 'implement' a contract specifying different contract terms in the event of a successful termination of another pair's negotiations and in the event instead of a breakdown in another pair's negotiations. This assumption captures the idea that bargaining parties cannot commit to a permanent and irrevocable breakdown in their negotiations.

We make the following assumption throughout:

Assumption 1: $\beta \geq \bar{\beta}(\gamma)=\frac{4 \gamma^{3}}{4-\gamma^{2}(5-2 \gamma)} \cdot{ }^{19}$

Assumption 1 is a necessary and sufficient condition in order to avoid the non-existence of pure strategy pairwise proof equilibria. Non-existence may occur because pairwise proofness leads to negative profits for the upstream monopolist, violating thus its individual rationality condition (McAfee and Schwartz, 1995; Rey and Vergé, 2004; and Milliou and Petrakis, 2007).

\section{$3 \quad$ FDI Modes in a Vertically Related Industry}

In this section, we determine the equilibrium of our model. In the last stage of the game, each $D_{i}$ chooses its $q_{i}$ in order to maximize its (gross) profits, $\pi_{D_{i}}=p_{i}\left(q_{i}, Q_{-i}\right) q_{i}-w_{i} q_{i}$, where $Q_{-i}=q_{j}$ under AQ with $i, j=m, 1$ and $Q_{-i}=q_{j}+q_{k}$ under GI, with $i, j, k=m, 1,2$ and $i \neq j \neq k .^{20}$ The first order conditions give rise to the following reaction functions:

$$
R_{i}\left(Q_{-i}, w_{i}\right)=\frac{a-w_{i}-\gamma Q_{-i}}{2}
$$

\footnotetext{
${ }^{18}$ Pairwise proofness is closely related to the passive beliefs assumption (see e.g. Hart and Tirole, 1990; McAfee and Schwartz, 1994 and 1995; Rey and Vergé, 2004; de Fontenay and Gans, 2005).

${ }^{19}$ Note that $\bar{\beta}(\gamma)$ is increasing in $\gamma$, with $\bar{\beta}(0)=0$ and $\bar{\beta}(0.7807)=1$.

${ }^{20} \mathrm{We}$ should note that we implicitly assume that in the case of AQ, the acquired firm continues to manufacture and sell only one product variety - it operates only its pre-existing production line - and thus, it does not manufacture or sell the product variety of the MNE's parent firm too. A justification for our assumption is that in our setting local production is necessary (exports are not possible) and that the setting up and the operation of two production lines can be too costly. A similar assumption can be found in Eicher and Kang (2005), Müller (2007), and Gabszewicz et al. (2011). Clearly, if we had assumed instead that the acquired firm manufactures two product varieties, then, as Lommerud et al. (2005) note, the acquired firm would be 'larger' and the incentives for AQ would be even stronger.
} 
Obviously, a reduction in the wholesale price faced by $D_{i}$ shifts its reaction function upwards and increases its aggressiveness in the final market. It is straightforward to derive the equilibrium quantities and the (gross) profits in terms of the wholesale prices under AQ:

$$
\begin{aligned}
q_{i}^{A Q}\left(w_{i}, w_{j}\right) & =\frac{a(2-\gamma)-2 w_{i}+\gamma w_{j}}{4-\gamma^{2}} ; \pi_{D_{i}}^{A Q}\left(w_{i}, w_{j}\right)=\left[q_{i}^{A Q}\left(w_{i}, w_{j}\right)\right]^{2} \\
\pi_{U}^{A Q}\left(w_{i}, w_{j}\right) & =\sum_{i=m, 1}\left(w_{i}-u\right) q_{i}^{A Q}\left(w_{i}, w_{j}\right)
\end{aligned}
$$

as well as under GI:

$$
\begin{aligned}
q_{i}^{G I}\left(w_{i}, w_{j}, w_{k}\right) & =\frac{a(2-\gamma)-2 w_{i}+\gamma\left(w_{j}+w_{k}-w_{i}\right)}{2(2-\gamma)(1+\gamma)} \\
\pi_{D_{i}}^{G I}\left(w_{i}, w_{j}, w_{k}\right) & =\left[q_{i}^{G}\left(w_{i}, w_{j}, w_{k}\right)\right]^{2} ; \quad \pi_{U}^{G I}\left(w_{i}, w_{j}, w_{k}\right)=\sum_{i=m, 1,2}\left(w_{i}-u\right) q_{i}^{G I}\left(w_{i}, w_{j}, w_{k}\right) \cdot(5)
\end{aligned}
$$

Next, we solve the second stage of the game, first, under GI, and then, under AQ.

\section{(i) Greenfield Investment}

Under GI, when $U$ bargains with $D_{i}$ over $\left(w_{i}, F_{i}\right)$, it takes as given the outcomes of its simultaneously run negotiations with the other two downstream firms, $\left(w_{j}^{G I}, F_{j}^{G I}\right)$ and $\left(w_{k}^{G I}, F_{k}^{G I}\right)$. In particular, $w_{i}$ and $F_{i}$ are chosen in order to solve the following generalized Nash product:

$$
\begin{aligned}
& \max _{w_{i}, F_{i}} {\left[\pi_{U}^{G I}\left(w_{i}, w_{j}^{G I}, w_{k}^{G I}\right)+F_{i}+F_{j}^{G I}+F_{k}^{G I}-d\left(w_{j}^{G I}, F_{j}^{G I}, w_{k}^{G I}, F_{k}^{G I}\right)\right]^{\beta} } \\
& \quad \times\left[\pi_{D_{i}}^{G I}\left(w_{i}, w_{j}^{G I}, w_{k}^{G I}\right)-F_{i}\right]^{1-\beta},
\end{aligned}
$$

where $d\left(w_{j}^{G I}, F_{j}^{G I}, w_{k}^{G I}, F_{k}^{G I}\right)=\left(w_{j}^{G I}-u\right) q_{j}^{A Q}\left(w_{j}^{G I}, w_{k}^{G I}\right)+\left(w_{k}^{G I}-u\right) q_{k}^{A Q}\left(w_{k}^{G I}, w_{j}^{G I}\right)+F_{j}^{G I}+F_{k}^{G I}$ is $U$ 's disagreement payoff, i.e., its profits when in the downstream market there are only $D_{j}$

and $D_{k}$ producing quantity $q_{k}^{A Q}\left(w_{k}^{G I}, w_{j}^{G I}\right)$ given by (2) facing the equilibrium contract terms $\left(w_{j}^{G I}, F_{j}^{G I}\right)$ and $\left(w_{k}^{G I}, F_{k}^{G I}\right)$. Maximizing (6) in terms of $F_{i}$ and rewriting it, we have:

$$
\begin{aligned}
\max _{w_{i}} & \pi_{U}^{G I}\left(w_{i}, w_{j}^{G I}, w_{k}^{G I}\right)+\pi_{D_{i}}^{G I}\left(w_{i}, w_{j}^{G I}, w_{k}^{G I}\right) \\
& -\left[\left(w_{j}^{G I}-u\right) q_{j}^{A Q}\left(w_{j}^{G I}, w_{k}^{G I}\right)-\left(w_{k}^{G I}-u\right) q_{k}^{A Q}\left(w_{k}^{G I}, w_{j}^{G I}\right)\right] .
\end{aligned}
$$

An immediate observation from (7) is that $w_{i}$ is chosen in order to maximize the joint surplus of $U$ and $D_{i}$ minus $U$ 's disagreement payoff -their "extra" joint surplus. The resulting equilibrium wholesale price ((8) below) is lower than the upstream marginal cost $u$ :

$$
w_{i}^{G I}=\frac{(2-\gamma)(1+\gamma) u-a \gamma^{2}}{2+\gamma(1-2 \gamma)}<u
$$

The reason for the subsidization of the downstream production by the upstream monopolist is its so called "commitment problem" (see e.g., McAfee and Schwartz, 1995, Rey and Vergé, 
2004, and de Fontenay and Gans, 2005). This refers to $U$ 's inability to commit to $D_{i}$ that it will not behave opportunistically and make $D_{j}$ an aggressive competitor in the final product market, via a lower $w_{j}$. $U$ has incentives to behave opportunistically because it can then use $F_{j}$ in order to transfer upstream the higher gross profits of $D_{j}$. By inspection of (8), we note that the equilibrium wholesale prices are independent of the bargaining power distribution and they decrease as the products become closer substitutes, $\partial w^{G I} / \partial \gamma<0$.

Substituting, we obtain the equilibrium firms' net profits under GI:

$$
\begin{aligned}
\pi_{D_{1}}^{G I} & =\pi_{D_{2}}^{G I}=\frac{(1-\beta)(2-\gamma)^{2}(a-u)^{2}}{4(2+\gamma)[2+\gamma(1-2 \gamma)]} ; \quad \pi_{D_{m}}^{G I}=\pi_{D_{1}}^{G I}-G \\
\pi_{U}^{G I} & =\frac{3(2-\gamma)\left[4 \beta-5 \beta \gamma^{2}-2(2-\beta) \gamma^{3}\right](a-u)^{2}}{4(2+\gamma)[2+\gamma(1-2 \gamma)]^{2}}
\end{aligned}
$$

It follows from (9) that GI is a profitable option only when $G<\bar{G} \equiv \frac{(1-\beta)(2-\gamma)^{2}(a-u)^{2}}{4(2+\gamma)[2+\gamma(1-2 \gamma)]}$.

\section{(ii) Cross-Border Acquisition}

Under AQ, $U$ bargains with $D_{i}$ over $\left(w_{i}, F_{i}\right)$, taking as given the outcome of its simultaneouslyrun two-part tariff negotiations with $D_{j},\left(w_{j}^{A Q}, F_{j}^{A Q}\right)$. The generalized Nash product now is:

$$
\max _{w_{i}, F_{i}}\left[\pi_{U}^{A Q}\left(w_{i}, w_{j}^{A Q}\right)+F_{i}+F_{j}^{A Q}-d\left(w_{j}^{A Q}, F_{j}^{A Q}\right)\right]^{\beta}\left[\pi_{D_{i}}^{A Q}\left(w_{i}, w_{j}^{A Q}\right)-F_{i}\right]^{1-\beta}
$$

where $d\left(w_{j}^{A Q}, F_{j}^{A Q}\right)=\left(w_{j}^{A Q}-u\right) q_{j}^{m}\left(w_{j}^{A Q}\right)+F_{j}^{A Q}$ with $q_{j}^{m}\left(w_{j}^{A Q}\right)=\left(a-w_{j}^{A Q}\right) / 2$, is $U$ 's disagreement payoff when $D_{j}$ acts as a monopolist in the final goods market facing $\left(w_{j}^{A Q}, F_{j}^{A Q}\right)$. Maximizing (11) in terms of $F_{i}$, and rewriting it, we observe again that the generalized Nash product reduces to an expression proportional to the "extra" joint surplus of $U$ and $D_{i}$, that $w_{i}$, in turn, is chosen to maximize:

$$
\max _{w_{i}} \pi_{U}^{A Q}\left(w_{i}, w_{j}^{A Q}\right)+\pi_{D_{i}}^{A Q}\left(w_{i}, w_{j}^{A Q}\right)-\left(w_{j}^{A Q}-u\right) q_{j}^{m}\left(w_{j}^{A Q}\right)
$$

Due to the commitment problem, the resulting equilibrium wholesale prices under AQ too are below the upstream marginal cost:

$$
w_{i}^{A Q}=\frac{\left(4-\gamma^{2}\right) u-a \gamma^{2}}{2\left(2-\gamma^{2}\right)}<u .
$$

Next, we determine the acquisition price. When the MNE makes its acquisition offer to $D_{2}$, it knows that the target firm will accept the offer if and only if the acquisition price is at least as high as the profits that it would obtain under the alternative entry mode, i.e., under GI when $G<\bar{G}$. Taking this into account, the MNE optimally sets $A^{*}=\pi_{D_{2}}^{G I}$ when $G<\bar{G}$. Thus, the 
resulting equilibrium net profits under AQ when $G<\bar{G}$ are:

$$
\begin{aligned}
\pi_{D_{1}}^{A Q} & =\frac{(1-\beta)(2-\gamma)^{2}(a-u)^{2}}{8\left(2-\gamma^{2}\right)} ; \pi_{D_{m}}^{A Q}=\pi_{D_{1}}^{A Q}-\pi_{D_{1}}^{G I} \\
\pi_{U}^{A Q} & =\frac{(2-\gamma)(a-u)^{2}\left[\beta(2-\gamma)\left(2-\gamma^{2}\right)-\gamma^{3}\right]}{4\left(2-\gamma^{2}\right)^{2}}
\end{aligned}
$$

One can easily check from (14) that the MNE makes positive profits under AQ when $G<\bar{G}$. When, instead, $G \geq \bar{G}$, it makes zero profits. This is so because when the MNE chooses only among AQ and no entry, when $D_{2}$ receives an acquisition offer, its outside option equals its profits under no entry, i.e., equals its profits under downstream duopoly. This, in turn, means that the acquisition price equals then the MNE's gross profits under AQ. It follows that when $G \geq \bar{G}$, the MNE is indifferent between undertaking FDI through AQ in the host market and not expanding there at all.

(ii) Greenfield Investment vs. Cross-Border Acquisition

We are now in the position to compare the two FDI modes and to determine which of them is chosen by the MNE in equilibrium.

Proposition 1 When $G<\bar{G}$, the equilibrium wholesale price is lower under GI than under $A Q, w_{i}^{G I}<w_{i}^{A Q}$.

As Proposition 1 states, the MNE sources the input at better terms - it pays a lower input price, when it establishes its own production plant locally rather than when it acquires a domestic firm. Intuitively, under GI there are more downstream firms in the market, and thus, there is fiercer competition. When downstream competition is fierce, $U$ 's incentives to behave opportunistically are stronger; hence, its commitment problem is more severe (see e.g., Rey and Tirole, 2006, Rey and Vergé, 2004).

Next, we determine the MNE's optimal FDI mode calculating the difference of its profits under the two modes:

$$
\pi_{D_{m}}^{A Q}-\pi_{D_{m}}^{G I}=\pi_{D_{1}}^{A Q}-\pi_{D_{1}}^{G I}-\left(\pi_{D_{1}}^{G I}-G\right)=\pi_{D_{1}}^{A Q}-2 \pi_{D_{1}}^{G I}+G
$$

If the wholesale price did not differ among the two modes and GI was costless $(G=0)$, then (16) would be negative, and thus, the MNE would prefer GI over AQ. This would be so because, as it is well known from oligopoly theory, a firm's profits in a market with two firms $\left(\pi_{D_{1}}^{A Q}\right)$ are lower than the sum of two downstream firms' profits in a market with three firms $\left(2 \pi_{D_{1}}^{G I}\right){ }^{21}$

\footnotetext{
${ }^{21}$ This is so because when the number of firms in a market reduces from three to two (e.g., due to a merger), then due to the "business stealing" effect indentified by Salant et al. (1988), each firm's market share becomes relative smaller than the combined market share of two firms under triopoly. We should note that in the more trivial case in which there was monopoly in the downstream market of the host country, the "business stealing" effect would not have been present, and thus, the incentives for AQ would be stronger than in our setting.
} 
Clearly, in our setting in which the MNE faces a lower marginal cost, due to the lower wholesale price, under GI than under AQ, (16) is even more negative, and hence, the MNE's incentives to choose GI instead of AQ are even stronger. Clearly, this implies that in our setting, GI arises in equilibrium as long as it is not sufficiently costly - $G$ is not too high. Otherwise, the MNE chooses to expand through AQ. The above discussion is formalized in the following Lemma.

Lemma 1 When $G<\bar{G}$, the $M N E$ chooses $G I$ over $A Q$ if and only if $G<G_{c r}(\beta, \gamma) \equiv$ $\frac{(1-\beta)(2-\gamma)^{2}\left[4-\gamma\left(4+\gamma-2 \gamma^{2}\right)\right](a-u)^{2}}{8(2+\gamma)\left(2-\gamma^{2}\right)\left(2+\gamma-2 \gamma^{2}\right)}$.

How the bargaining power distribution among the vertically related firms influences the FDI mode choice? The answer to this question is provided by Proposition 2(i) that states that as the upstream supplier's bargaining power increases, the MNE's incentives to choose AQ over GI are reinforced. This happens for the following reason. When the upstream supplier's bargaining power increases, its share of the surplus gets larger. Clearly, this means that the MNE's gross profits decrease then. This occurs under AQ as well as under GI. The decrease in the latter case, i.e., the decrease in the MNE's gross profits under the GI mode, however, has a positive impact on the MNE's net profits under AQ because it translates into a lower acquisition price. In other words, when the upstream supplier becomes more powerful, AQ gets cheaper, and thus, more desirable relative to GI.

Proposition 2 When $G<\bar{G}$, the $M N E$ is more likely to choose AQ over GI:

(i) when the upstream firm's bargaining power increases, $\frac{\partial G_{c r}}{\partial \beta}<0$, and

(ii) when products substitutability increases, $\frac{\partial G_{c r}}{\partial \gamma}<0$.

Proposition 2(ii) informs us about the role of the intensity of downstream competition in the choice of FDI mode: as the products become closer substitutes, and thus, as downstream competition gets stronger, it becomes more probable to observe AQ instead of GI in equilibrium. There are two explanations behind this result. The first explanation has to do with the fact that there is weaker competition in the market under AQ than under GI since there are fewer firms in the market in the former case. When product substitutability increases and competition intensifies, the benefit of the weaker competition under AQ becomes more pronounced and as a result the MNE's incentives to choose AQ over GI are raised then. The second explanation has to do with the fact that the augmentation of competition brings about a reduction in the MNE's gross profits under both AQ and GI. As explained above, the resulting decrease in the gross profits under GI has a positive impact on the MNE's net profits under AQ. ${ }^{22}$

Given that in developed countries the MNEs tend to face more powerful input providers and stronger downstream competition than in less developed countries, one could claim that

\footnotetext{
${ }^{22}$ Note that Eicher and Kang (2005), Müller, (2007), and Qiu and Wang (2011) have found that in one-tier markets too, GI becomes less likely to be chosen relative to AQ when competition intensifies.
} 
our findings provide support to the empirically observed tendency of the MNEs to expand through Greenfield Investment in less developed countries and through cross-border M\&As in developed countries (UNCTAD, 2008 and 2012).

\section{Contract Terms' Observability and Contract Type}

We now consider, first, the implications of the contract terms' observability, and second, of the contract type, for our main results.

\subsection{Fully Unobservable Contracts}

So far we have assumed that the downstream firms observe each other's contract terms before making their quantity decisions. Now, we consider the polar case of interim unobservability in which the rivals' contract terms remain unknown throughout the game. This modification has an important implication: the contract terms do no longer have a strategic effect on the downstream quantities. In particular, in the last stage now, each $D_{i}$ chooses its own quantity anticipating that its rival(s) receive the equilibrium contract offer(s), and thus, produce the equilibrium quantity, $Q_{-i}^{e}$, where $e=A Q_{U}$ and $e=G I_{U}$ respectively under AQ and GI. Formally, $D_{i}$ chooses $q_{i}$ that maximizes its gross profits, $\pi_{D_{i}}=p_{i}\left(q_{i}, Q_{-i}^{e}\right) q_{i}-w_{i} q_{i}$. It is straightforward to derive $D_{i}$ 's output, $q_{i}\left(w_{i}\right)$, and to note that, in contrast to the case of interim observability, it depends only on the wholesale price that $D_{i}$ has to pay and not on the wholesale prices paid by its rival(s).

In the previous stage, the generalized Nash product under AQ is given again by (11) after substituting $A$ with $A U$ in it. Maximizing (11) in terms of $F_{i}$ and substituting the resulting $F_{i}$, we observe that $w_{i}$ is chosen in order to maximize the following:

$$
\max _{w_{i}}\left[a-q_{i}\left(w_{i}\right)-\gamma q_{j}^{A Q_{U}}-u\right] q_{i}\left(w_{i}\right)+\left(w_{j}^{A Q_{U}}-u\right) q_{j}^{A Q_{U}}+q_{j}^{m}\left(w_{j}^{A Q_{U}}\right)
$$

Note that $w_{i}$ affects (17) only through $\left[a-q_{i}\left(w_{i}\right)-\gamma q_{j}^{A Q_{U}}-u\right] q_{i}\left(w_{i}\right)$, which by construction is maximized when $q_{i}(u)$. Therefore, in equilibrium the wholesale prices under AQ are equal to the upstream marginal cost, $w_{i}^{A Q_{U}}=u .{ }^{23}$ The same rationale leads to marginal cost pricing by $U$ under GI too, $w_{i}^{G I_{U}}=u$. As a consequence, the equilibrium quantities under AQ and GI coincide with the quantities of a standard Cournot game respectively with two and three firms in the market and marginal cost $u$. It follows that firms' profits under GI are:

$$
\pi_{D_{m}}^{G I_{U}}=\frac{(1-\beta)(a-u)^{2}}{4(1+\gamma)^{2}}-G ; \pi_{D_{1}}^{G I_{U}}=\pi_{D_{2}}^{G I_{U}}=\frac{(1-\beta)(a-u)^{2}}{4(1+\gamma)^{2}} ; \pi_{U}^{G I_{U}}=\frac{3 \beta(a-u)^{2}}{4(1+\gamma)^{2}}
$$

Note that $\pi_{D_{m}}^{G I_{U}}>0$ if and only if $G<\bar{G}^{U} \equiv \frac{(1-\beta)(a-u)^{2}}{4(1+\gamma)^{2}}$.

\footnotetext{
${ }^{23}$ For more details on this, see e.g., Hart and Tirole (1990), Rey and Vergé (2004).
} 
Given that, for the reasons explained earlier, $A^{U}=\pi_{D_{2}}^{G I_{U}}$ when $G<\bar{G}^{U}$, firms' profits under AQ are then:

$$
\pi_{D_{m}}^{A Q_{U}}=\frac{(1-\beta)(a-u)^{2}}{4}\left(\frac{4}{(2+\gamma)^{2}}-\frac{1}{(1+\gamma)^{2}}\right) ; \pi_{D_{1}}^{A Q_{U}}=\frac{(1-\beta)(a-u)^{2}}{(2+\gamma)^{2}} ; \pi_{U}^{G I_{U}}=\frac{2 \beta(a-u)^{2}}{(2+\gamma)^{2}}
$$

Calculating the difference between the MNE's profits under AQ and GI, $\pi_{D_{m}}^{A Q_{U}}-\pi_{D_{m}}^{G I_{U}}$, we find that the MNE expands through GI instead of through AQ if and only if $G<G_{c r}^{U}(\beta, \gamma) \equiv$ $\frac{(1-\beta)\left(2-\gamma^{2}\right)(a-u)^{2}}{2(1+\gamma)^{2}(2+\gamma) 2}$, with $0<G_{c r}^{U}<\bar{G}^{U}$. Importantly, we find again that an increase in the upstream bargaining power, as well as an increase in product substitutability, by causing a decrease in the acquisition price, favor AQ relative to GI, $\frac{\partial G_{c r}^{U}}{\partial \gamma}<0$ and $\frac{\partial G_{c r}^{U}}{\partial \beta}<0$. Therefore, our conclusions regarding the role of the bargaining power distribution and the intensity of downstream competition do not depend on whether or not the contract terms are interim observable.

Proposition 3 When $G<\bar{G}^{U}, A Q$ is more likely to take place relative to GI when contract terms are interim unobservable than when they are interim observable.

According to Proposition 3, when the MNE extends into a market in which downstream firms do not get informed about their rivals' contract terms, it has more incentives to choose AQ over GI than when it expands, instead, into a market where they get informed before they make their output decisions. Intuitively, under interim unobservability, the FDI mode has no effect on the equilibrium wholesale prices. Whereas, under interim observability, GI results into lower wholesale prices than AQ; hence, under interim observability GI, has an advantage relative to AQ which is missing under interim unobservability. Clearly, this advantage makes GI more attractive under interim observability than under interim unobservability.

\subsection{Linear Contracts}

We examine now what happens under trading through wholesale price contracts as well as how the contract type affects the FDI mode choice.

When the MNE undertakes GI, $U$ bargains in stage two with $D_{i}$ over $w_{i}$, taking as given $w_{j}^{G I_{W}}$ and $w_{k}^{G I_{W}}$. The generalized Nash product is now:

$$
\max _{w_{i}}\left[\pi_{U}^{G I}\left(w_{i}, w_{j}^{G I_{W}}, w_{k}^{G I_{W}}\right)-d\left(w_{j}^{G I_{W}}, w_{k}^{G I_{W}}\right)\right]^{\beta}\left[\pi_{D_{i}}^{G I}\left(w_{i}, w_{j}^{G I_{W}}, w_{k}^{G I_{W}}\right)\right]^{1-\beta}
$$

where $\pi_{U}^{G I}($.$) and \pi_{D_{i}}^{G I}($.$) are given by (5)$ and $d\left(w_{j}^{G I_{W}}, w_{k}^{G I_{W}}\right)=\left(w_{j}^{G I_{W}}-u\right) q_{j}^{A Q}\left(w_{j}^{G I_{W}}, w_{k}^{G I_{W}}\right)+$ $\left(w_{k}^{G I_{W}}-u\right) q_{k}^{A Q}\left(w_{k}^{G I_{W}}, w_{j}^{G I_{W}}\right)$ is $U$ 's disagreement payoff when $D_{j}$ and $D_{k}$ act as duopolists with input prices $w_{j}^{G I_{W}}$ and $w_{k}^{G I_{W}}$. The resulting equilibrium wholesale prices and net profits 
are:

$$
\begin{aligned}
w_{i}^{G I_{W}} & =\frac{1}{2} \beta(a-u)+u ; \quad \pi_{D_{m}}^{G I_{W}}=\frac{(2-\beta)^{2}(a-u)^{2}}{16(1+\gamma)^{2}}-G ; \\
\pi_{D_{1}}^{G I_{W}} & =\pi_{D_{2}}^{G I_{W}}=\frac{(2-\beta)^{2}(a-u)^{2}}{16(1+\gamma)^{2}} ; \quad \pi_{U}^{G I_{W}}=\frac{3(2-\beta) \beta(a-u)^{2}}{8(1+\gamma)}
\end{aligned}
$$

One can easily observe that $\pi_{D_{m}}^{G I_{W}}>0$ only when $G<\bar{G}^{W} \equiv \frac{(2-\beta)^{2}(a-u)^{2}}{16(1+\gamma)^{2}}$.

When the MNE expands, instead, through $\mathrm{AQ}$, in stage two $U$ and $D_{i}$ maximize the generalized Nash product:

$$
\max _{w_{i}}\left[\pi_{U}^{A Q}\left(w_{i}, w_{j}^{A Q_{W}}\right)-d\left(w_{j}^{A Q_{W}}\right)\right]^{\beta}\left[\pi_{D_{i}}^{A Q_{i}}\left(w_{i}, w_{j}^{A Q_{W}}\right)\right]^{1-\beta}
$$

where $w_{j}^{A Q_{W}}$ is the equilibrium wholesale price charged to $D_{j}, \pi_{U}^{A Q}($.$) and \pi_{D_{i}}^{A Q}($.$) are given$ respectively by (2) and (3), and $d\left(w_{j}^{A Q_{W}}\right)=\left(w_{j}^{A Q_{W}}-u\right) q_{j}^{m}\left(w_{j}^{A Q_{W}}\right)$ is $U$ 's disagreement payoff when $D_{j}$ acts as a downstream monopolist with input price $w_{j}^{A Q_{W}}$. The equilibrium wholesale prices are:

$$
w_{i}^{A Q_{W}}=\frac{1}{2} \beta(a-u)+u .
$$

Note from (19) and (22) that the equilibrium wholesale prices, first, exceed the upstream marginal cost - double marginalization is present - and second, that they are the same under the two FDI modes. The latter means that under wholesale price contracts, as Dhillon and Petrakis (2002) have also shown, the equilibrium input prices are independent of the number of downstream firms.

We turn next to the determination of the equilibrium acquisition price. When $G<\bar{G}^{W}$, the MNE optimally sets $A^{W}=\pi_{D_{2}}^{G I_{W}}$, and the resulting equilibrium net profits are:

$$
\begin{aligned}
\pi_{D_{m}}^{A Q_{W}} & =\frac{1}{16}(a-u)^{2}(2-\beta)^{2}\left[\frac{4}{(2+\gamma)^{2}}-\frac{1}{(1+\gamma)^{2}}\right] \\
\pi_{D_{1}}^{A Q_{W}} & =\frac{(2-\beta)^{2}(a-u)^{2}}{4(2+\gamma)^{2}} ; \quad \pi_{U}^{A Q_{W}}=\frac{(2-\beta) \beta(a-u)^{2}}{2(2+\gamma)}
\end{aligned}
$$

From the comparison of $\pi_{D_{m}}^{G I_{W}}$ and $\pi_{D_{m}}^{A Q_{W}}$, it follows that the MNE chooses GI over AQ only when $G<G_{c r}^{W}(\beta, \gamma) \equiv \frac{(2-\beta)^{2}\left(2-\gamma^{2}\right)(a-u)^{2}}{8\left(2+3 \gamma+\gamma^{2}\right)^{2}}$, with $0<G_{c r}^{W}<\bar{G}^{W}$. Importantly, under wholesale price contracts too, the incentives of the MNE to choose AQ over GI increase when the upstream bargaining power increases as well as when products become closer substitutes, $\frac{\partial G_{c r}^{W}}{\partial \beta}<0$ and $\frac{\partial G_{c r}^{W}}{\partial \gamma}<0$. The driving mechanism behind these findings is similar to the respective one under two-part tariff contracts.

Next, we consider the role of the contract type for the FDI mode choice. We know that under two-part tariffs, GI has an advantage relative to AQ which is absent under wholesale price contracts: it leads to a lower input price, and thus, lower marginal cost for the MNE. In 
light of this, we would expect that GI is more likely to be chosen relative to AQ under two-part tariffs than under wholesale price contracts. According to Proposition 4 this is the case only when the upstream supplier is not powerful enough - in area II of Figure 1.

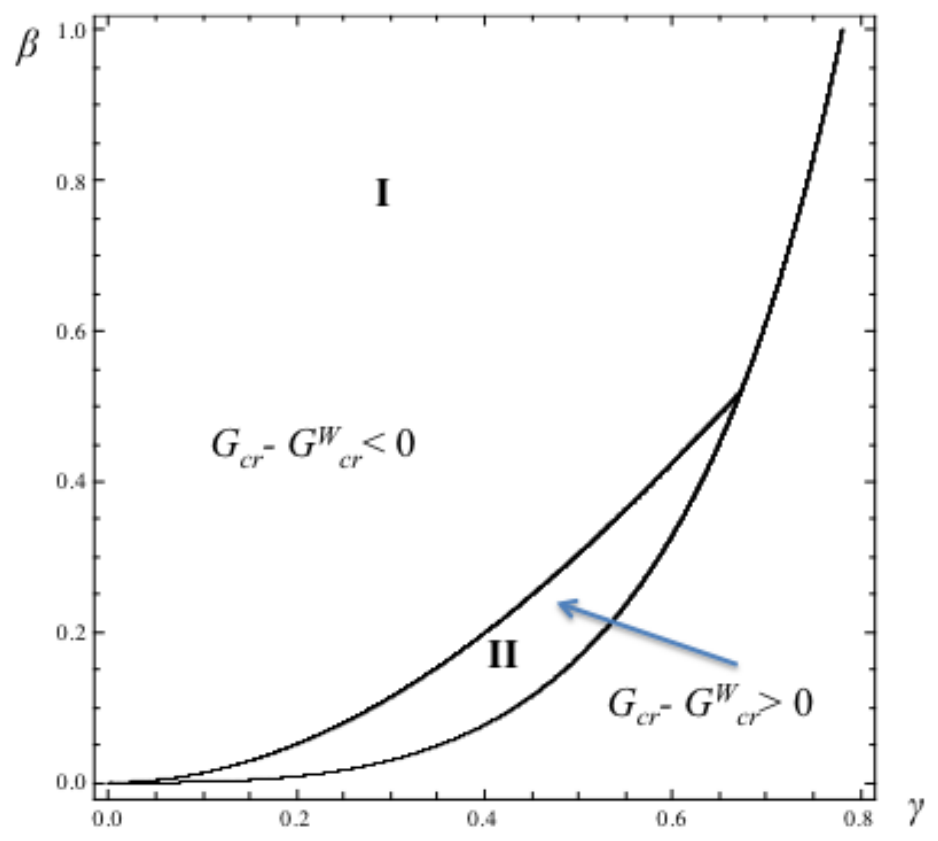

Figure 1: The Role of the Contract Types

Proposition 4 When $G<\min \left\{\bar{G}, \bar{G}^{W}\right\}, A Q$ is more likely to take place relative to GI when trading is through two-part tariff contracts than through wholesale price contracts unless the upstream bargaining power is sufficiently low.

When the upstream bargaining power is high enough, two-part tariffs favor AQ relative to GI more than wholesale price contracts. This result is driven by the fixed fees that are present only in the case of two-part tariffs. The fixed fees allow $U$ to extract a higher share of the joint surplus. As a result, the MNE appropriates under two-part tariffs less of the higher, due to the lower marginal cost, joint surplus of GI than under wholesale price contracts.

\section{The Role of Backward Linkages}

In this section, we explore how the presence of backward linkages affects the FDI mode choice. In order to do so, first, we determine the MNE's optimal FDI mode in a one-tier market where backward linkages are absent, and then, we compare it with the respective one in a vertically related market with backward linkages.

In modelling the one-tier market, we assume that the host country's market consists of two competing domestic firms that face the potential entry of the MNE. We also assume that both the domestic firms and the MNE produce the input in house with marginal cost $u$. It is 
noteworthy that the results of this model coincide with the results of a model in which firms obtain the input from a perfectly competitive upstream sector. This means that the analysis of this section, also allows us to characterize the role of the upstream market structure, upstream monopoly versus upstream perfect competition, for the FDI mode choice.

Proposition 5 AQ is more likely to take place relative to GI in a vertically related industry than in a one-tier industry. This holds under two-part tariff contracts, independently of whether they are interim observable or interim unobservable, as well as under wholesale price contracts.

As Proposition 5 states, the presence of backward linkages favors AQ relative to GI. Importantly, the positive impact of the backward linkages on the MNE's incentives to choose AQ over GI holds independently of the contract terms' observability and of whether two-part tariffs or wholesale price contracts are used. This suggests that the intuition behind this finding is of a more general nature. In particular, this finding is not driven by the fact that in a vertically related market the MNE faces the same (under interim unobservable two-part tariffs), lower (under interim observable two-part tariffs) or higher (under wholesale price contracts) marginal cost than in a one-tier market. It is driven, instead, by the fact that in the presence of backward linkages, the downstream firms do not fully extract the surplus that they generate in the market - the upstream supplier gets part of the surplus through the contract terms. Interestingly, under two-part tariffs, this is so even when the upstream monopolist does not have any bargaining power $(\beta=0)$ since even then the downstream firms need to compensate $U$, through a positive fixed fee, for its "outside option". A consequence of this is that the MNE's gross profits under AQ, as well as under GI, are lower in a vertically related market than the respective ones in a one-tier market. The higher gross profits under GI in a one-tier market clearly translate into a higher acquisition price; hence, they make AQ more expensive in such a market. This last effect smoothens the difference in the MNE's net profits under $\mathrm{AQ}$ in the absence and in the presence of backward linkages and makes it smaller than the respective difference among the MNE's profits under GI. Stated in different words, this effect makes the preference of AQ over GI weaker in a one-tier market than in a vertically related market.

Our above finding suggests that the empirically documented dominance of cross-border M\&As relative to greenfield investments in developed countries, could arise because in such countries the MNEs invest in sectors in which they depend heavily on input suppliers. In line with this, our finding also gives rise to the following testable implication: AQ is more likely to be observed relative to GI in industries where firms obtain inputs from a concentrated upstream market than in industries where inputs are either produced in-house or sourced from a perfectly competitive upstream market. 


\section{Domestic Welfare and FDI Modes}

In this section, we examine the impact of FDI, and of its different modes, on the host country's economy.

We start by noting that the structure of the host market under autarky (TK), i.e., when there is no entry, is the same as in the case of entry through AQ. This has the following implication: $U$ 's profits, as well as $D_{1}$ 's profits, are equal under AQ and TK, but not under GI. The fact that under GI there are more downstream firms in the market means that there are also more backward linkages and that the input demand is higher. Because of this, the domestic upstream supplier tends to be better off when the MNE enters through GI rather than when it enters through AQ or when it does not enter at all. This holds always when trading is conducted through wholesale price contracts. When, instead, trading is conducted through two-part tariffs, it holds only as long as product substitutability is not too strong ( $\gamma$ is sufficiently low). In the case of interim observable two-part tariff contracts, this is due to the adverse effect that, as explained in section 3, GI has on the commitment problem. In the case of interim unobservable two-part tariff contracts, this arises because the downstream firms extract a larger share of the surplus when the outside option of the upstream firm is weaker, i.e., when there are fewer downstream firms in the market as it is the case under AQ. From the perspective of the non-acquired $D_{1}$, GI is always less desirable than AQ/TK. This suggests that the effect of the enhanced downstream competition under GI offsets the effect of the potentially higher, due to the lower input prices, downstream efficiency under interim observability and GI. The same rationale holds also for the acquired $D_{2}$. Still, since the profits of the acquired firm under $\mathrm{AQ}$ are equal to its profits under GI, $D_{2}$ is indifferent among AQ and GI, but it has a clear preference of autarky over AQ or GI.

Next, we ask how the two FDI entry patterns differ in terms of their impact on the host country's consumer and total welfare as well as whether FDI makes the host country better off relative to autarky.

As noted above, the market structure, and thus, the equilibrium input prices and output are the same under autarky and acquisition. As a consequence, consumers' surplus is equal under entry through AQ and no entry at all. In contrast, consumers' surplus is higher under GI than AQ/TK because of the higher, downstream competition and the potentially (under interim unobservability) also higher downstream efficiency under GI than under AQ/TK. This is formally stated in Proposition 6.

Proposition 6 When $G<\min \left\{\bar{G}, \bar{G} U, \bar{G}^{W}\right\}$, consumers' surplus is always higher under GI than under $A Q / T K$. This holds under two-part tariff contracts, independently of whether they are interim observable or interim unobservable, as well as under wholesale price contracts.

Turning to total welfare, we should clarify that in its measurement, we exclude the profits 
of the MNE. Obviously, this means that our subsequent welfare discussion is different from the welfare discussion in a model without MNEs.

Proposition 7 When $G<\min \left\{\bar{G}, \bar{G}^{U}, \bar{G}^{W}\right\}$ and trading is through:

(i) interim observable two-part tariffs, then $W^{G I}>W^{T K}>W^{A Q}$,

(ii) interim unobservable two-part tariffs, then $W^{G I_{U}}>W^{T K_{U}}>W^{A Q_{U}}$ if the upstream bargaining power is sufficiently high; otherwise, $W^{T K_{U}}>W^{G I_{U}}>W^{A Q_{U}}$,

(iii) wholesale price contracts, then $W^{G I_{W}}>W^{T K_{W}}>W^{A Q_{W}}$ if the upstream bargaining power is sufficiently high; otherwise, $W^{T K_{W}}>W^{G I_{W}}>W^{A Q_{W}}$.

From Proposition 7, it follows that AQ and GI have different implications on the host country's welfare; the host country is strictly better off with GI than with AQ. This holds both with two-part tariff contracts, independently of whether they are interim observable or not, and with wholesale price contracts. The logic behind this finding is as follows: the expansion that GI causes in the market demand, both downstream and upstream, benefits more the consumers and the upstream supplier than it hurts $D_{1}$.

From Proposition 7, it also follows that FDI is welfare-detrimental when it is through AQ, i.e., the AQ mode always leads to a reduction in the host country's total welfare relative to autarky. The opposite holds for the GI - it is welfare-increasing - when interim observable two-part tariff contracts are used. When, instead, interim unobservable two-part tariffs or linear wholesale price contracts are used, and thus, GI does not result into higher downstream efficiency than autarky, the GI mode is welfare-increasing only if the upstream bargaining power is sufficiently high. This is so because the upstream monopolist suffers then less more from the commitment problem under GI than under AQ/TK, and thus, the positive impact that GI has, through the increased input demand, on its profits is more pronounced when it has high bargaining power and extracts a high share of the surplus.

When GI is not a viable option because it is too costly, Proposition 7 is no longer relevant. The welfare comparison is restricted then to that among autarky and AQ. Under AQ though the acquisition price is equal to the profits of the domestic downstream firm under autarky. Therefore, consumer and total welfare are equal then with AQ and with autarky.

Regarding the implications of FDI in a one-tier market, given that GI results in such a market too into more intense competition compared to AQ and autarky, it is not surprisingly that consumers are again always better off under GI than under AQ/TK. ${ }^{24}$ However, GI is not necessary always welfare-enhancing in a one-tier industry. Indeed, in a one-tier industry, although welfare is always higher with GI than with AQ, it is lower with GI than with autarky when the market is highly competitive $(\gamma>0.464)$. In other words, when market competition is already fierce, the loss in domestic profits from the further intensification of competition

\footnotetext{
${ }^{24}$ The detailed analysis is available from the authors upon request.
} 
with GI is so strong that it offsets its the positive impact on consumers' surplus. This happens because in a one-tier industry, as opposed to what happens in a vertically related industry, GI does not generate vertical linkages in the domestic market or it does not lead to increased efficiency.

The above results suggest that the host country's government should treat the two modes of FDI differently, and importantly, that it should not always welcome FDI. More specifically, they give rise to the following policy conclusions. First, when the MNE's choice is AQ, i.e., when the fixed cost of GI is not sufficiently low, the host country's government should take measures that discourage AQ. For instance, it could impose restrictions on the maximum profit shares that the MNEs could obtain from the acquired domestic firms so that they are driven away from AQ. These restrictions, which vary across countries as well as across industries within a country, are the most popular FDI policy among many countries (UNCTAD, 2000).

Second, when GI is too costly, the host countries' government should offer incentives, such as subsidies, to the MNEs when they set up production plants in the local market. This should always be the case when two-part tariffs are used and the government also imposes regulations that dictate the disclosure of the contract terms. When, instead, either the contract terms are not observable or wholesale price contracts are used, this should be the case only if the domestic input suppliers are powerful enough since then GI always results into higher welfare than autarky and the MNE's incentives to choose AQ over GI are stronger. We should stress though that the government should undertake measures that induce GI only as long as the burden of such measures on the country's budget is smaller than the benefits generated by GI. Clearly, in order to provide more detailed policy implications on the basis of our theoretical results, we would need to model rigorously the set of policy instruments and their costs.

Third, we provide two arguments in favor of the use of regulations that mandate the disclosure of the vertical contract terms. Such regulations can cause, first, the increase in the downstream efficiency under greenfield investment, and second, they can decrease the MNE's incentives to expand through the welfare-detrimental acquisition mode rather than through greenfield investment.

Fourth, the host country's government should vary its policy among different industry sectors. It should be more keen in applying measures that promote the entry of MNEs through GI in vertically related industry sectors with concentrated upstream sectors than in vertically related industries with competitive upstream markets or in industries where firms do not depend heavily on input suppliers especially when the latter sectors are very competitive.

\section{Concluding Remarks}

We have analyzed a MNE's choice of FDI mode, acquisition of a foreign firm or greenfield investment, along with the implications of the different FDI modes on market outcomes and 
on the host country's welfare. We have performed our analysis using a framework which is motivated by the observation that although real world FDI often takes place in vertical related industries and results in local input sourcing, the existing literature on the choice of FDI mode has focused exclusively on one-tier industries.

Our analysis has pointed out that FDI is more likely to take the form of a cross-border acquisition in markets with more powerful domestic upstream suppliers as well as in markets with more intense downstream competition. This is so because the lower profits of the MNE in such markets under greenfield investment translate into a lower acquisition price, and thus, they make the acquisition mode cheaper, and hence, more attractive.

Our analysis has also highlighted the importance of a number of contracting features. In particular, we have concluded that the contract type used can influence the MNE's choice of expansion mode: non-linear two-part tariff contracts, by allowing the upstream supplier to extract more surplus through the fixed fees, tend to favor acquisition relative to greenfield investment more than wholesale price contracts. In contrast, the observability of the contract terms before the competition in the downstream market takes place, and thus, the regulations that impose it, can have an adverse effect on the MNE's incentives to choose acquisition over greenfield investment. Importantly, we have concluded that the existence of vertical linkages favors more the acquisition mode. This holds even when greenfield investment has an advantage relative to acquisition in a vertically related industry, which is absent in a one-tier industry: it results into higher (downstream) efficiency. An important insight underlying this result is that in the presence of backward linkages and two-part tariffs, the entering MNE does not fully enjoy the surplus generated by its FDI; part of the surplus goes to the local upstream supplier.

FDI through acquisition causes a decrease rather an increase in both the consumer and the total welfare of the host country. This is so because while both FDI modes result into a decrease in the profits of one of the domestic downstream firms, acquisition, in contrast to greenfield investment, neither generates additional backward linkages nor it intensifies downstream competition in the host country relative to autarky. The enhanced, instead, downstream competition along with the potentially also increased efficiency through the lower input prices, caused by greenfield investment increase its desirability from the host country's consumers' surplus viewpoint relative not only to acquisition but also to autarky. This holds especially when the domestic upstream firm takes more advantage of the increased input demand under greenfield investment, i.e., when it has a lot of bargaining power.

Summing up, our paper adds value to the literature on FDI in three main aspects. First, it demonstrates that the structure of the market, and in particular, the existence of backward linkages, can be crucial for the choice of FDI mode. Second, it provides an alternative explanation for the dominance of cross-border M\&As in some countries based on the consideration of vertically related industries and their features, such as the concentration in the upstream market and the distribution of the bargaining power among the vertically related firms. Third, 
it points out that the presence of vertical linkages along with the specific characteristics of different industry sectors, should not be ignored in the design of policy measures for attracting different FDI modes. The host country's FDI policy should be designed in such a way that distinguishes among the different FDI modes as well as among different industry sectors, such as sectors with more or less competitive upstream and downstream markets, or sectors with more or less dependence on intermediate products.

We should mention that most of our results regarding the FDI mode choice and its implications on the host country's economy extend also to the case of downstream competition in prices as long as final products are not too close substitutes. ${ }^{25}$ In the latter case, given that prices are strategic complements instead of substitutes, downstream competition is too intense and thus, a further increase in its intensity through greenfield investment, is less desirable from the perspective not only of the MNE but also of the domestic input supplier.

Still, our paper is only a first step in the direction of endogenizing a MNE's choice of expansion mode in the presence of local vertical linkages. In a following step, one could also explore the MNE's choice in a vertical related industry characterized by upstream oligopoly or vertical integration. ${ }^{26}$ Similarly, one could examine how the alternative FDI modes affect the MNE's incentives for vertical technology transfer and along with their subsequent implications through this additional channel. Finally, one could include exports as an alternative option to FDI. This could alter the cost of acquisition since the alternative entry mode would not necessarily only be greenfield investment, and therefore, it could affect the MNE's choice of FDI mode. A complication that would arise then is that one would have to specify how the input price that the MNE faces in its home market is determined. That is, one would have to fully model also the market structure and the trading in the MNE's home market. Clearly, the latter would increase significantly the degree of complication of the analysis. These are left for future research.

\section{Appendix}

Proof of Proposition 1: We calculate the difference of (8) and (13):

$$
w_{i}^{G I}-w_{i}^{A Q}=-\frac{(2-\gamma) \gamma^{2}(a-u)}{2\left(2-\gamma^{2}\right)[2+\gamma(1-2 \gamma)]}<0
$$

\footnotetext{
${ }^{25}$ The details are available from the authors upon request.

${ }^{26}$ We should note that serious complications arise in situations in which rival upstream firms deal with the same competing downstream firms and trade through non-linear contracts. As mentioned in a recent review article by Miklós-Thal et al. (2010, p.345) "The formal modeling of such "interlocking" vertical relations has proved difficult... and we still know relatively little about many basic questions... Interlocking relationships cause modeling issues such as either the inexistence or a large multiplicity of equilibria even in simple competition games." Similarly, Inderst (2010, p.343) states that "... the benchmark model where competing upstream firms simultaneously make take-it-or-leave-it offers to competing downstream firms, may fail to have an equilibrium in pure strategies." Beladi et al. (2013) have considered a domestic market characterized by vertical integration.
} 
It follows immediately that $w_{i}^{G I}<w_{i}^{A Q}$.

Proof of Lemma 1: We set the difference in the MNE's net profits between the GI and the AQ mode ((9) and (14)), equal to zero, $\pi_{D_{m}}^{G I}-\pi_{D_{m}}^{A I}=0$, and solving for $G$, we obtain:

$$
G_{c r}(\beta, \gamma) \equiv\left(2 \pi_{D_{1}}^{G I}-\pi_{D_{1}}^{A Q}\right)=\frac{(1-\beta)(2-\gamma)^{2}[4-\gamma(4+\gamma(1-2 \gamma))](a-u)^{2}}{8(2+\gamma)\left(2-\gamma^{2}\right)[2+\gamma(1-2 \gamma)]}
$$

We note that $\bar{G}-G_{c r}(\beta, \gamma)=\pi_{D_{1}}^{G}-\left(2 \pi_{D_{1}}^{G}-\pi_{D_{1}}^{A}\right)=\pi_{D_{1}}^{A}-\pi_{D_{1}}^{G}>0$. We also note that $G_{c r}(\beta, \gamma)>0$. Moreover, we note that given that $G<\bar{G}$, we have $\pi_{D_{m}}^{G}-\pi_{D_{m}}^{A}>0$ if $G<G_{c r}(\beta, \gamma)$ and $\pi_{D_{m}}^{G}-\pi_{D_{m}}^{A}<0$ if $G>G_{c r}(\beta, \gamma)$.

Proof of Proposition 2: (i) We differentiate $G_{c r}(\beta, \gamma)$ in terms of $\beta$, and we find:

$$
\frac{\partial G_{c r}}{\partial \beta}=-\frac{(1-\beta)(2-\gamma)\left[48-\gamma\left(48+\gamma\left(72-\gamma\left(72+\gamma\left(31-\gamma\left(35+4 \gamma-6 \gamma^{2}\right)\right)\right)\right)\right)\right](a-u)^{2}}{2(2+\gamma)^{2}\left(2-\gamma^{2}\right)^{2}(2+\gamma(1-2 \gamma))^{2}}
$$

The denominator is clearly positive. The expression in the numerator within the brackets is also positive. Thus, due to the negative sign in the front part of the derivative, we have $\frac{\partial G_{c r}}{\partial \beta}<0$

(ii) Differentiating $G_{c r}(\beta, \gamma)$ in terms of $\gamma$, we obtain:

$$
\frac{\partial G_{c r}}{\partial \gamma}=-\frac{(2-\gamma)^{2}[4-\gamma(4+\gamma(1-2 \gamma))](a-u)^{2}}{8(2+\gamma)\left(2-\gamma^{2}\right)[2+\gamma(1-2 \gamma)]}
$$

The denominator and the numerator are both positive. Given this and the negative sign in the front part of the derivative, we have $\frac{\partial G_{c r}}{\partial \gamma}<0$.

Proof of Proposition 3: We know, from Lemma 1, that under interim observable two-part tariffs, the MNE expands through GI instead of AQ if and only if $G<G_{c r}$. Under interim unobservable two-part tariffs, it expands through GI rather than through AQ if and only if $G<G_{c r}^{U}$. Comparing the two critical values of $G, G_{c r}$ and $G_{c r}^{U}$, we have:

$$
G_{c r}(\beta, \gamma)-G_{c r}^{U}(\beta, \gamma)=\frac{(1-\beta) \gamma^{4}[14+\gamma(3+\gamma(2+\gamma)(2 \gamma-5))](a-u)^{2}}{8(1+\gamma)^{2}(2+\gamma)^{2}\left(2-\gamma^{2}\right)(2+\gamma(1-2 \gamma))} .
$$

Both the numerator and the denominator of the above expression are positive. Thus, $G_{c r}(\beta, \gamma)>$ $G_{c r}^{U}(\beta, \gamma)$. This, in turn, means that the condition that should be satisfied in order for GI to be chosen in equilibrium instead of AQ is stricter under interim unobservability.

Proof of Proposition 4: We know, from Lemma 1, that under two-part tariffs, the MNE expands through GI instead of AQ if and only if $G<G_{c r}$. Under wholesale price contracts, it expands through GI rather than through AQ if and only if $G<G_{c r}^{W}$. Setting the difference between the two critical values of $G$ equal to zero, $M_{W}(\beta, \gamma) \equiv G_{c r}(\beta, \gamma)-G_{c r}^{W}(\beta, \gamma)=0$, and 
solving for $\beta$, we obtain:

$$
\beta_{W}(\gamma) \equiv \frac{-14 \gamma^{4}-3 \gamma^{5}+10 \gamma^{6}+\gamma^{7}-2 \gamma^{8}-(2-\gamma) \gamma^{2}(1+\gamma) \sqrt{X}}{2\left(2-\gamma^{2}\right)^{2}[2+\gamma(1-2 \gamma)]}
$$

where $X=(2+\gamma)[14+\gamma(3-\gamma(2+\gamma)(5-2 \gamma))][4-\gamma(4+\gamma(1-2 \gamma))]$.

We find that $\beta_{W}(0)=0, \beta_{W}(0.6728772)=\bar{\beta}(0.672872)=0.519558, \frac{\partial \beta_{W}}{\partial \gamma}>0, \lim _{\beta \rightarrow 1} M_{W}(\beta, \gamma)=$ $-\frac{\left(2-\gamma^{2}\right)(a-u)^{2}}{8\left(2+3 \gamma+\gamma^{2}\right)^{2}}<0$, and $\lim _{\beta \rightarrow 0} M_{W}(\beta, \gamma)=\frac{\gamma^{4}[14+\gamma(3-\gamma(2+\gamma)(5-2+\gamma))](a-u)^{2}}{8(1+\gamma)^{2}(2+\gamma)^{2}\left(2-\gamma^{2}\right)(2+\gamma(1-2 \gamma))}>0$. Combining all these, it follows that $M_{W}(\beta, \gamma)>0$ if $\beta<\beta_{W}(\gamma)$, and $M_{W}(\beta, \gamma)<0$ if $\beta>\beta_{W}(\gamma)$. Thus, when $G \leq \min \left\{\bar{G}, \bar{G}^{W}\right\}$, the condition that should be satisfied in order for GI to be chosen in equilibrium instead of $\mathrm{AQ}$ is stricter under two-part tariff contracts than under wholesale price contracts, unless $\beta<\beta_{W}(\gamma)$.

Proof of Proposition 5: In the case of a one-tier market, each firm $i$, chooses $q_{i}$ in order to maximize its profits, $\pi_{D_{i}}=p_{i}\left(q_{i}, Q_{-i}\right) q_{i}-u q_{i}$, where $Q_{-i}=q_{j}$ under AQ with $i, j=m, 1$ and $Q_{-i}=q_{j}+q_{k}$ under GI, with $i, j, k=m, 1,2$ and $i \neq j \neq k$. The first order conditions under GI and $\mathrm{AQ}$ result respectively into the following equilibrium quantities: $q_{i}^{G I_{O}}=(a-u) / 2(1+\gamma)$ and $q_{i}^{A Q_{O}}=(a-u) /(2+\gamma)$. The respective resulting equilibrium profits under GI are: $\pi_{m}^{G I_{O}}=$ $\left[q_{i}^{G I_{O}}\right]^{2}-G ; \pi_{1}^{G I_{O}}=\pi_{1}^{G I_{O}}=\left[q_{i}^{G I_{O}}\right]^{2}$. Clearly, GI is a viable option for the MNE only when $\pi_{m}^{G I_{O}}>0$. This holds when $G<\bar{G}^{O} \equiv \frac{(a-u)^{2}}{4(1+\gamma)^{2}}$. In the case of AQ, when $G<\bar{G}^{O}$, the equilibrium acquisition price is $A^{O}=\pi_{1}^{G I_{O}}$ and the MNE's profits are: $\pi_{m}^{A Q_{O}}=\left[q_{i}^{A Q_{O}}\right]^{2}-\pi_{1}^{G}$. In order to identify the equilibrium FDI mode, we set $\pi_{m}^{G I_{O}}-\pi_{m}^{A Q_{O}}=0$ and solving for $G$ we find that, when $G \leq \bar{G}^{O}$, the MNE chooses GI over AQ if and only if $G<G_{c r}^{O}$, where $G_{c r}^{O}(\gamma) \equiv \frac{\left(2-\gamma^{2}\right)(a-u)^{2}}{2\left(2+3 \gamma+\gamma^{2}\right)^{2}}$. We also find that $0<G_{c r}^{O} \leq \bar{G}^{O}$ and $\frac{\partial G_{c r}^{O}}{\partial \gamma}<0$.

Comparing the critical value in the one-tier market, $G_{c r}^{O}(\gamma)$, with the critical value in a vertically related market under trading through interim observable two-part tariffs, we have:

$$
G_{c r}(\beta, \gamma)-G_{c r}^{O}(\gamma)=-(a-u)^{2}\left[\frac{2-\gamma^{2}}{2\left(2+3 \gamma+\gamma^{2}\right)^{2}}+\frac{(1-\beta)(2-\gamma)^{2}[4-\gamma(4+\gamma(1-2 \gamma))]}{8(2+\gamma)\left(2-\gamma^{2}\right)[(2 \gamma-1) \gamma-2]}\right]
$$

The expression within the brackets is always positive. Thus, $G_{c r}(\beta, \gamma)<G_{c r}^{O}(\gamma)$. This means that the condition that should be satisfied in order for GI to be chosen in equilibrium instead of $\mathrm{AQ}$ is stricter in a vertically related market with interim observable two-part tariff contracts than in a one-tier market.

Next, we compare $G_{c r}^{U}(\beta, \gamma)$ with $G_{c r}^{O}(\gamma)$ :

$$
G_{c r}^{U}(\beta, \gamma)-G_{c r}^{O}(\gamma)=-\frac{\beta\left(2-\gamma^{2}\right)(a-u)^{2}}{2(1+\gamma)^{2}(2+\gamma)^{2}}
$$

Obviously the above expression is negative; hence, $G_{c r}^{U}(\beta, \gamma)<G_{c r}^{O}(\gamma)$, i.e., the condition that should be satisfied in order for GI to be chosen in equilibrium over AQ is stricter in a vertically related market with interim unobservable two-part tariff contracts than in a one-tier market. 
Finally, we compare $G_{c r}^{W}(\beta, \gamma)$ with $G_{c r}^{O}(\gamma)$ :

$$
G_{c r}^{W}(\beta, \gamma)-G_{c r}^{O}(\gamma)=-\frac{(4-\beta) \beta\left(2-\gamma^{2}\right)(a-u)^{2}}{8\left(2+3 \gamma+\gamma^{2}\right)^{2}}
$$

The above difference is clearly negative. Thus, the condition that should be satisfied in order for GI to be chosen in equilibrium instead of AQ is stricter in a vertically related market with wholesale price contracts than in a one-tier market.

Proof of Proposition 6: In the case of AQ as well as in the case of TK, consumers' surplus is given by $C S^{A Q}=\left(q_{i}^{A Q}\right)^{2}+\gamma\left(q_{i}^{A Q}\right)^{2}$ under interim observable two-part tariffs. Under interim unobservable two-part tariffs, it is given by $C S^{A Q_{U}}=\left(q_{i}^{A Q_{U}}\right)^{2}+\gamma\left(q_{i}^{A Q_{U}}\right)^{2}$, and under wholesale price contracts, by $C S^{A Q_{W}}=\left(q_{i}^{A Q_{W}}\right)^{2}+\gamma\left(q_{i}^{A Q_{W}}\right)^{2}$.

In the case of GI, consumers' surplus is given by $C S^{Z}=\frac{1}{2}\left[3\left(q_{i}^{Z}\right)^{2}+6 \gamma\left(q_{i}^{Z}\right)^{2}\right]$, with $Z=G I$ under interim observable two-part tariffs, $Z=G I_{U}$ under interim unobservable contracts, and $Z=G I_{W}$ under wholesale-price contracts.

Calculating the differences between the consumers' surplus in the case of GI and the consumers' surplus in the case of $\mathrm{AQ} / \mathrm{TK}$, we find:

$$
\begin{aligned}
C S^{G I}-C S^{A Q} & =\frac{1}{8}(2-\gamma)^{2}\left[\frac{3+6 \gamma}{\left(2+\gamma-2 \gamma^{2}\right)^{2}}-\frac{2(1+\gamma)}{\left(2-\gamma^{2}\right)^{2}}\right](a-u)^{2}>0 \\
C S^{G I_{U}}-C S^{A Q_{U}} & =\left[\frac{3(1+2 \gamma)}{8(1+\gamma)^{2}}-\frac{1+\gamma}{(2+\gamma)^{2}}\right](a-u)^{2}>0 \\
C S^{G I_{W}}-C S^{A Q_{W}} & =\left[\frac{3(1+2 \gamma)}{32(1+\gamma)^{2}}-\frac{1+\gamma}{4(2+\gamma)^{2}}\right](2-b)^{2}(a-u)^{2}>0 .
\end{aligned}
$$

Therefore, when $G \leq \min \left\{\bar{G}, \bar{G}^{U}, \bar{G}^{W}\right\}$, consumers' surplus is always higher under GI than under AQ/TK.

Proof of Proposition 7: The total welfare of the host country is given by $W^{R}=C S^{R}+\pi_{U}^{R}+$ $2 \pi_{D_{1}}^{R}$ under TK, by $W^{S}=C S^{S}+\pi_{U}^{S}+\pi_{D_{1}}^{S}+\pi_{D_{2}}^{X}$ under AQ, and by $W^{Y}=C S^{Y}+\pi_{U}^{Y}+2 \pi_{D_{1}}^{Y}$ under GI when $G \leq \min \left\{\bar{G}, \bar{G}^{U}, \bar{G}^{W}\right\}$, where the consumers's surplus can be found in the proof of Proposition 6 and $R=T K, T K_{U}, T K_{W}, S=A Q, A Q_{U}, A Q_{W}$ and $Y=G I, G I_{U}, G I_{W}$ depending on whether interim observable or unobservable two-part tariffs or wholesale price contracts are used.

(i) Assuming that interim observable two-part tariffs are used, we calculate the following:

$$
\begin{aligned}
W^{G I}-W^{T K}= & \frac{1}{8}(2-\gamma)(a-u)^{2} \\
& *\left[\frac{28+2 \beta\left(4-\gamma^{2}(5-2 \gamma)\right)+\gamma(24-\gamma(23+22 \gamma))}{(2+\gamma)\left(2+\gamma-2 \gamma^{2}\right)^{2}}-\frac{2\left(6-\gamma-3 \gamma^{2}\right)}{\left(2-\gamma^{2}\right)^{2}}\right] ; \\
W^{T K}-W^{A Q}= & \frac{(1-\beta)(2-\gamma)^{2} \gamma\left(4-\gamma-2 \gamma^{2}\right)(a-u)^{2}}{8(2+\gamma)\left(2-\gamma^{2}\right)(2+\gamma(1-2 \gamma))} .
\end{aligned}
$$


It is straightforward to check that both of the above expressions are positive; hence, $W^{G I}>$ $W^{T K}>W^{A Q}$.

(ii) We assume now that trading takes place through interim unobservable contracts. We calculate the following differences:

$$
\begin{aligned}
W^{G I_{U}}-W^{A Q_{U}} & =\frac{\left[4 \beta\left(2-\gamma^{2}\right)+(2+\gamma)(2+\gamma(1-2 \gamma))\right](a-u)^{2}}{8(1+\gamma)^{2}(2+\gamma)^{2}} \\
W^{T K_{U}}-W^{A Q_{U}} & =\frac{(1-\beta) \gamma(4+3 \gamma)(a-u)^{2}}{4(1+\gamma)^{2}(2+\gamma)^{2}}
\end{aligned}
$$

Clearly, both of them are positive. Thus, $W^{G I_{U}}>W^{A Q_{U}}$ and $W^{T K_{U}}>W^{A Q_{U}}$.

We set the difference between welfare under GI and welfare under TK equal to zero, $M_{W}^{U}(\beta, \gamma) \equiv W^{G I_{U}}-W^{T K_{U}}=0$ and solving for $\beta$, we obtain:

$$
\beta_{W}^{U}(\gamma) \equiv \gamma-\frac{4+(4-\gamma) \gamma}{2(2+\gamma)^{2}}
$$

We find that $\beta_{W}^{U}(0.464)=0, \beta_{W}^{U}(1)=0.611$, and $\frac{\partial \beta_{W}^{U}}{\partial \gamma}>0$. We also find that $\lim _{\beta \rightarrow 1} M_{W}^{U}(\beta, \gamma)=$ $\frac{1}{8}\left(\frac{9+6 \gamma}{(1+\gamma)^{2}}-\frac{8(3+\gamma)}{(2+\gamma)^{2}}\right)>0$ and $\lim _{\beta \rightarrow 0} M_{W}^{U}(\beta, \gamma)=\frac{1}{8}\left(\frac{7+6 \gamma}{(1+\gamma)^{2}}-\frac{8(3+\gamma)}{(2+\gamma)^{2}}\right)<0$ when $\gamma>0.464$. Combining all these, we can claim that $M_{W}^{U}(\beta, \gamma)>0$ if $\beta>\beta_{W}^{U}(\gamma)$, and $M_{W}^{U}(\beta, \gamma)<0$ if $\beta<\beta_{W}^{U}(\gamma)$. In other words, $W^{G I_{U}}>W^{T K_{U}}$ if and only if $\beta>\beta_{W}^{U}(\gamma)$.

(iii) In the case of trading through wholesale price contracts, it is straightforward that the following two differences are positive:

$$
\begin{aligned}
W^{G I_{W}}-W^{A Q_{W}} & =\frac{(2-\beta)\left[4+6 \beta+(2+3 \beta) \gamma-2(2+\beta) \gamma^{2}\right](a-u)^{2}}{32(1+\gamma)^{2}(2+\gamma)} \\
W^{T K_{W}}-W^{A Q_{W}} & =\frac{(2-\beta)^{2} \gamma(4+3 \gamma)(a-u)^{2}}{16(1+\gamma)^{2}(2+\gamma)^{2}}
\end{aligned}
$$

Therefore, $W^{G I_{W}}>W^{A Q_{W}}$ and $W^{T K_{W}}>W^{A Q_{W}}$.

Finally, we set the difference between welfare under GI and welfare under TK equal to zero, $M_{W}^{W}(\beta, \gamma) \equiv W^{G I_{W}}-W^{T K_{W}}=0$ and solving for $\beta$, we obtain:

$$
\beta_{W}^{W}(\gamma) \equiv \frac{2[(4+\gamma) \gamma(1+2 \gamma)-4]}{(3+2 \gamma)[4+(4-\gamma) \gamma]}
$$

It is straightforward to check that $\beta_{W}^{W}(0.464)=0, \beta_{W}^{W}(1)=0.628, \frac{\partial \beta_{W}^{W}}{\partial \gamma}>0, \lim _{\beta \rightarrow 1} M_{W}^{W}(\beta, \gamma)=$ $\frac{1}{32}\left(\frac{19+18 \gamma}{(1+\gamma)^{2}}-\frac{8(7+3 \gamma)}{(2+\gamma)^{2}}\right)>0$, and $\lim _{\beta \rightarrow 0} M_{W}^{W}(\beta, \gamma)=\frac{4-\gamma(4+\gamma)(1+2 \gamma)}{8(1+\gamma)^{2}(2+\gamma)^{2}}<0$ when $\gamma>0.464$. From all these, it follows that $M_{W}^{W}(\beta, \gamma)>0$ if $\beta>\beta_{W}^{W}(\gamma)$, and $M_{W}^{W}(\beta, \gamma)<0$ if $\beta<\beta_{W}^{W}(\gamma)$, i.e., $W^{G I_{W}}>W^{T K_{W}}$ if and only if $\beta>\beta_{W}^{W}(\gamma)$. 


\section{References}

Arya, A. and B. Mittendorf (2011), "Disclosure Standards for Vertical Contracts," Rand Journal of Economics, 42, 595-617.

Balsvik, R. (2010), "Multinationals' Mode of Entry with Presence of Upstream Spillovers," Economica, 77, 334-351.

Barrios, S., H. Gorg and E. Strobl (2011), "Spillovers through Backward Linkages from Multinationals: Measurement Matters!," European Economic Review, 55, 862-875.

Beladi, H., A. Chakrabarti and S. Marjit (2013), "Cross-Border Mergers in Vertically Related Industries," European Economic Review, 59, 97-108.

Blalock, G. and P. Gertler (2008), "Welfare Gains from Foreign Direct Investment through Technology Transfer to Local Suppliers," Journal of International Economics, 74, 202-221.

Bjorvatn, K. (2004), "Economic Integration and the Profitability of Cross-Border Mergers and Acquisitions," European Economic Review, 48, 1211-1226.

Bonnet, C. and P. Dubois (2010), "Inference on Vertical Contracts between Manufacturers and Retailers Allowing for Non-Linear Pricing and Resale Price Maintenance," Rand Journal of Economics, 41, 139-164.

Caprice, S. (2006), "Multilateral Vertical Contracting with an Alternative Supply: The Welfare Effects of a Ban on Price Discrimination," Review of Industrial Organization, 28, 63-80.

Carluccio, J. and T. Fally (2013), "Foreign Entry and Spillovers with Technological Incompatibilities in the Supply Chain," Journal of International Economics, 90, 123-135.

Cremer, J. and M. H. Riordan (1987), "On Governing Multilateral Transactions with Bilateral Contracts," Rand Journal of Economics, 18, 436-451.

de Fontenay, C. C. and J. S. Gans (2005), "Vertical Integration in the Presence of Upstream Competition," Rand Journal of Economics, 36, 544-572.

Dhillon, A. and E. Petrakis (2002), "A Generalized Wage Rigidity Result," International Journal of Industrial Organization, 20, 285-311.

Eicher, T. and J. W. Kang (2005), "Trade, Foreign Direct Investment or Acquisition: Optimal Entry Modes for Multinationals," Journal of Development Economics, 77, 207-228.

Gabszewicz, J., D. Laussel and O. Tarola (2011), "To Acquire, or to Compete? An Entry Dilemma," Journal of Industry, Competition and Trade, 4, 369-383.

Giroud, A. (2007), "MNEs Vertical Linkages: The Experience of Vietnam after Malaysia," International Business Review, 16, 159-176.

Goh, A. (2005), "Knowledge Diffusion, Input Supplier's Technological Effort and Technology Transfer via Vertical Relationships," Journal of International Economics, 66, 527-540.

Hart, O. and J. Tirole (1990), "Vertical Integration and Market Foreclosure," Brookings Papers on Economic Activity, Microeconomics, 205-276. 
Horn, H. and L. Persson (2001), "The Equilibrium Ownership of an International Oligopoly," Journal of International Economics, 53, 307-333.

Horn, H. and A. Wolinsky (1988), "Bilateral Monopolies and Incentives for Mergers," Rand Journal of Economics, 19, 408-419.

Inderst, R. (2010), "Models of Vertical Relations," International Journal of Industrial Organization, 28, 341-344.

Ivarsson, I. and C. G. Alvstam (2005), "Technology Transfer from TNCs to Local Suppliers in Developing Countries: A Study of AB Volvo's Truck and Bus Plants in Brazil, China, India, and Mexico," World Development, 33, 1325-1344.

Javorcik, B. S.(2004), "Does Foreign Direct Investment Increase the Productivity of Domestic Firms? In Search of Spillovers Through Backward Linkages," American Economic Review, 94, 605-627.

Jordaan, J. A. (2011), "FDI, Local Sourcing, and Supportive Linkages with Domestic Suppliers: The Case of Monterrey, Mexico," World Development, 36, 2838-2854.

Lin, P. and K. Saggi (2007), "Multinational Firms, Exclusivity, and Backward Linkages," Journal of International Economics, 71, 206-220.

Lin, P. and K. Saggi (2011), "FDI in a Two-Tier Oligopoly: Coordination, Vertical Integration, and Welfare," International Economic Review, 52, 1271-1290.

Liu, B. H. (2011), "MNEs and Local Linkages: Evidence from Taiwanese Affiliates," World Development, 39, 633-647.

Lommerud, K. E., O. R. Straume, and L. Sorgard (2005), "Downstream Merger with Upstream Market Power," European Economic Review, 49, 717-743.

Ma, J. (2012), "Double-Edged Incentive Competition for Foreign Direct Investment," unpublished manuscript, University of International Business and Economics.

Ma, J. (2013), "Market Size, Local Sourcing and Policy Competition for Foreign Direct Investment," Review of International Economics, 21, 984-995.

Markusen, J. R. and A. Venables (1999), "Foreign Direct Investment as a Catalyst for Industrial Development," European Economic Review, 43, 335-356.

Mattoo, A., M. Olarreaga and K. Saggi (2004), "Mode of Foreign Entry, Technology Transfer, and FDI Policy," Journal of Development Economics, 75, 95-111.

McAfee, P. and M. Schwartz (1994), "Opportunism in Multilateral Vertical Contracting: Non-discrimination, Exclusivity, and Uniformity," American Economic Review, 84, 210-230.

McAfee, P. and M. Schwartz (1995), "The Non-Existence of Pairwise-Proof Equilibrium," Economics Letters, 49, 251-259.

Miklós-Thal, J., P. Rey, and T. Vergè (2010), "Vertical Relations," International Journal of Industrial Organization, 28, 345-349.

Milliou, C. (2013), "Location of Foreign Direct Investment in Vertically Related Markets," Review of International Economics, forthcoming. 
Milliou, C. and E. Petrakis (2007), "Upstream Horizontal Mergers, Vertical Contracts, and Bargaining," International Journal of Industrial Organization, 25, 963-987.

Milliou, C. and A. Pavlou (2013), "Upstream Mergers, Downstream Competition and R\&D Investments," Journal of Economics and Management Science, 22, 787-809.

Müller, T. (2007), "Analyzing Modes of Foreign Entry: Greenfield Investment versus Acquisition," Review of International Economics, 15, 93-111.

Neary, P. (2007), "Cross-Border Mergers as Instruments of Comparative Advantage," Review of Economic Studies, 74, 1229-1257.

Nocke, V. and S. Yeaple (2007), "Cross-Border Mergers and Acquisitions versus Greenfield Foreign Direct Investment: The Role of Firm Heterogeneity," Journal of International Economics, 72, 336-365.

Nocke, V. and S. Yeaple (2008), "An Assignment Theory of Foreign Direct Investment," Review of Economic Studies, 75, 529-557.

Norbäck, P.-J. and L. Persson (2004), "Globalization and Profitability of Cross-Border Mergers and Acquisitions," Economic Theory, 35, 241-266.

O'Brien, D. and G. Shaffer (1992), "Vertical Control with Bilateral Contracts," Rand Journal of Economics, 23, 299-308.

Pack, H. and K. Saggi (2001), "Vertical Technology Transfer via International Outsourcing," Journal of Development Economics, 65, 389-415.

Qiu, L. and Z. Tao (2001), "Export, Foreign Direct Investment, and Local Content Requirement," Journal of Development Economics, 66, 101-125.

Piccolo, S. and J. Miklós-Thal (2012), "Colluding through Suppliers," Rand Journal of Economics, 43, 492-513.

Qiu, L. and S. Wang (2011), "FDI Policy, Greenfield Investment and Cross-Border Mergers," Review of International Economics, 19, 836-851.

Qiu, L. and W. Zhou (2006), "International Mergers: Incentives and Welfare," Journal of International Economics, 68, 38-58.

Raff, H., M. Ryan and F. Stahler (2009), "The Choice of Market Entry Mode: Greenfield Investment, M\&A and Joint Venture," International Review of Economics and Finance, 18, $3-10$.

Rey, P. and J. Tirole (2007), "A Primer on Foreclosure," Handbook of Industrial Organization, vol. III, 2145-2220.

Rey, P. and T. Vergé (2004), "Bilateral Control with Vertical Contracts," Rand Journal of Economics, 35, 728-746.

Rodriguez-Clare, A. (1996), "Multinationals, Linkages, and Economic Development," American Economic Review, 86, 852-873.

Salant, S. W., S. Switzer and R. J. Reynolds (1983), "Losses from Horizontal Merger: The Effect of an Exogenous Change in Industry Structure on Cournot-Nash Equilibrium," 
Quarterly Journal of Economics, 98, 185-199.

Smith, H. and J. Thanassoulis (2009), "Bargaining Between Retailers and Their Suppliers", in A. Ezrachi and U. Bernitz (eds.), Private Labels, Brands and Competition Policy, Oxford University Press.

UNCTAD (1999), World Investment Report 1999, United Nations, New York and Geneva.

UNCTAD (2000), World Investment Report 2000, United Nations, New York and Geneva.

UNCTAD (2004), World Investment Report 2000, United Nations, New York and Geneva.

UNCTAD (2006), World Investment Report 2000, United Nations, New York and Geneva.

UNCTAD (2008), World Investment Report 2008, United Nations, New York and Geneva.

UNCTAD (2012), World Investment Report 2012, United Nations, New York and Geneva.

Villas-Boas, S. (2007) "Vertical Relationships between Manufacturers and Retailers: Inference with Limited Data," Review of Economic Studies, 74, 625-652.

World Bank (2003), "Developing Knowledge Intensive Sectors, Technology Transfers, and the Role of FDI," Foreign Investment Advisory Service, Washington, DC. 